\title{
Effect of the process parameters on magnesium alloy using the submerged friction stir process
}

\author{
R. Sankar, V. S. Senthilkumar* \\ Department of Mechanical Engineering, CEG, Anna University, Tamilnadu, India
}

Received 19 August 2016, received in revised form 24 April 2019, accepted 2 May 2019

\begin{abstract}
In the present work, the hot rolled AZ31B magnesium alloy plate of $6 \mathrm{~mm}$ thickness is subjected to a friction stir process (FSP) under submerged condition. The process parameters of FSP considered are tool pin profile (simple cylindrical, stepped cylindrical, stepped square), rotational tool speed, and traverse speed. The output responses considered in this study are microhardness, elongation, and ultimate tensile strength. TOPSIS (Technique for Order of Preference by Similarity to Ideal Solution), a new method is used for optimizing the multiple responses. ANOVA showed the tool pin profile as a most influencing parameter. The results indicated the stepped square pin profiled tool with a rotational speed of $1000 \mathrm{rpm}$ and a traverse rate of $30 \mathrm{~mm} \mathrm{~min}^{-1}$ exhibited a superior surface property by grain refinement, which increased the microhardness and mechanical properties in the nugget zone of the processed material.
\end{abstract}
Key words: submerged friction stir processing, welding, processing, TOPSIS (Technique for Order of Preference by Similarity to Ideal Solution), microstructure, tool pin profiles, magnesium alloy, mechanical properties

\section{Introduction}

Among the currently known processing techniques in the industry, Friction Stir Processing (FSP) is the solid-state process used for modifying the microstructure. It improves the mechanical properties arising out of the Friction Stir Welding (FSW) developed and designed by TWI Ltd., Cambridge, the United Kingdom, in 1991. In FSP, a non-consumable rotating tool with a shoulder and a pin is embedded in the workpiece of the material and traverses along the desired path for localized microstructural variation for specific property improvement in the nugget zone arising from severe plastic deformation (SPD), blending, and thermal presentation of the metal. Magnesium alloys, the lightest products among constructional material, find extensive use in the transport and aerospace industry sectors [1-3]. The findings of many research works indicate the FSP of magnesium alloys as capable of grain refinement and homogenization of the microstructure in a single pass FSP [4-6]. Vivek et al. [7] who carried out the FSP of pin profile, report effective pin area as a key factor for determining friction deformation and hence heat generation. This effective total pin area consists of a lateral surface and a tip area. Conical pin recorded the lowest value of the temperature at all the plunge depths as a result of the lowest value of the total pin area. Motalleb-Nejad et al. [8] investigated the mechanical properties and microstructure changes in FSW on AZ31B Mg alloy through the effect of the tool pin profile. They found the thread and tapered pin profile producing good properties and fine grain refinement with a defect-free weld when compared to other pin profiles. However, Elangovan et al. [9] carried out the FSP of the AA2219 alloy through the influence of five various design profiles of the tool pin. Their results show that square pin geometry achieved considerable microhardness, superior tensile strength, and very fine grain refinement at the traverse rate of $0.75 \mathrm{~mm} \mathrm{~s}^{-1}$. Ramesh Babu et al. [10] conducted experiments on the AZ31B alloy. They indicated the $24 \mathrm{~mm}$ tool shoulder diameter produced a better defect-free surface. The results of their investigation also indicated the enhancement of ductility in the work material and ultrafine

*Corresponding author: e-mail addresses: vssk70@gmail.com, vsskumar@annauniv.edu 
grains in the FSP zone. Karthikeyan et al. [11] investigated the superplastic formation in the FSP of the aluminum alloy. They achieved the successful formation of friction stir processed sheets. They carried out finite element modeling and theoretical modeling using exclusive software. They found agreement between the experimental and theoretical results. Douglas et al. [12] carried out the SFSP of ultra-fine grained bulk materials. They used water as the medium for the submersion of the bulk material and found a significant reduction in the conduction heat flow (due to the addition of water) when compared with air. They found the grain size reduction to be below $200 \mu \mathrm{m}$. Fang Chai et al. [13] acquired this by the application of submerged friction stir processing (SFSP) of AZ91 series magnesium alloy. They also found SFSP producing a remarkable grain refinement. Achievement of remarkably enhanced superplasticity when compared to the normal FSP also redounds to their credit. Rathinasuriyan et al. [14] carried out the SFSW of AA6061-T6 aluminum alloy using RSM. They observed microstructure variation and mechanical properties during FSW and SFSW, with the result showing the achievement of fine grain structure in SFSW samples compared to FSW samples. Improved changes in the mechanical properties and microstructure have also been observed. Zhang et al. [15] studied the fracture appearance and microstructural variation in the FSW joint for Al 2024 alloy. An achievement of FSW weld sample nugget zone of superior and equiaxed crystal grains was the result. When the traverse rate was $300 \mathrm{~mm} \mathrm{~min}^{-1}$, a higher tensile strength of the welded joints $294 \mathrm{MPa}$ was achieved, just as much as $70 \%$ of the values for the parent materials. They correlated the results with the microstructure and fracture features.

Later authors [6-19] carried out experiments under submerged conditions and reported results produced by the submerged combination as superior to those from conventional FSP/FSW. The peak temperature of the SFSP sample was lower when related to the conventional FSP/FSW sample. The mechanical and microstructural changes in the submerged welding/processing indicated improved properties over the conventional FSW/FSP material. The above studies show SFSP as one of the important processes used in industries. Previous researchers saw improvements in the mechanical properties and grain refinement of materials. These studies reveal the absence of any systematic and comparative approach in the study on the SFSP. In this investigation, a systematic approach using Taguchi $\mathrm{L}_{27}$ was chosen, and the processing of parameters was done using the TOPSIS method. Senthilkumar et al. [20] conducted submerged friction stir welding together with multi-response tool pin profiles using the TOPSIS approach. The results of their work indicate microhard- ness higher than that of friction stir welded metal in the stir zone as a result of grain refinement. Yuvaraj et al. [21] carried out multi-response optimization for abrasive-aqua jet machining process parameters using the TOPSIS technique. They identified the optimal cutting parameters and their levels using the TOPSIS method. Lokesh et al. [22] carried out FSW/FSP in submerged condition and obtained results found to be better compared to normal FSW/FSP. The maximum peak temperature of the submerged samples was much lower than that for the normal FSW/FSP samples. The tensile strength, percentage elongation and microhardness value of material processed by submerged welding were better than those of the normal FSW material. Maity Chakraborty et al. [23] studied abrasive material selection for a grinding wheel using the fuzzy TOPSIS method. They achieved the multi-performance target using the TOPSIS method. Jamshidi et al. [24] explored the influence of welding parameters on mechanical properties and microstructure through the use of FSW. They demonstrated the achievement of better grain refinement and increased microhardness during FSW by lower traverse speed and rotational speed.

Research works in the field of submerged friction stir processing have been rather few. There has been no investigation in the optimization of stepped tool pin profiles for SFSP till date. In the present work, the SFSP of AZ31B magnesium alloy was investigated with various features of stepped tool pin profiles (simple cylindrical, stepped cylindrical, and stepped square). Optimization of the SFSP parameters has also been carried out by using the TOPSIS technique. Also, the microstructural evaluation and subsequent effect of various pin profiles, rotational rate, and traverse speeds have been presented and discussed.

\section{Material and methods}

Plate of magnesium AZ31B alloy $(250 \mathrm{~mm} \times$ $200 \mathrm{~mm} \times 6 \mathrm{~mm}$ ) was used in this investigation. Tables 1 and 2 show the mechanical properties and chemical composition of the AZ31B alloy.

Tools having a scrolled shoulder surface of $24 \mathrm{~mm}$ diameter and varying pin profiles, including a simple cylindrical (CL), stepped cylindrical (SCL), and stepped square (SSQ) were fabricated using the H13 tool steel. They have a microhardness of approximately 60 HRC. There is a scroll introduced for all tools for facilitating the microstructural change effect. This prevents the tunneling defect in the processed workpiece, which is the novel feature of the present investigation. The tool dimensions used for the preparation of the tool pins and fabricated pin profiles are presented in Fig. 1. The experiments were carried out in the 3 -axis servo controlled friction stir 
Table 1. Chemical composition of AZ31B alloy (wt.\%)

\begin{tabular}{ccccccc}
\hline $\mathrm{Al}$ & $\mathrm{Mn}$ & $\mathrm{Si}$ & $\mathrm{Zn}$ & $\mathrm{Fe}$ & $\mathrm{Cu}$ & $\mathrm{Mg}$ \\
\hline 2.80 & 0.35 & 0.030 & 0.88 & 0.028 & 0.0020 & Balance \\
\hline
\end{tabular}

Table 2. Mechanical properties of AZ31B magnesium alloy

\begin{tabular}{ccc}
\hline $\begin{array}{c}\mathrm{UTS} \\
\left(\mathrm{N} \mathrm{mm}^{-2}\right)\end{array}$ & $\begin{array}{c}\mathrm{YS} \\
\left(\mathrm{N} \mathrm{mm}^{-2}\right)\end{array}$ & $\begin{array}{c}\text { Elongation } \\
\%\end{array}$ \\
\hline 255 & 217 & 10 \\
\hline
\end{tabular}
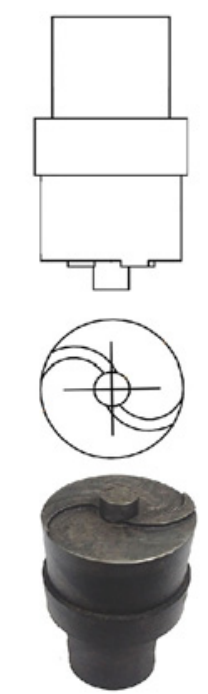

Simple Cylindrical (CL)
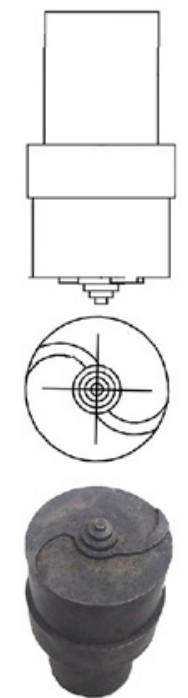

Stepped Cylindrical(SCI)
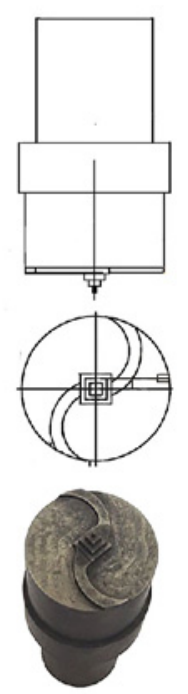

Stepped Square(SSQ)
Fig. 1. Specification of tool pin profile and measurements.

processing machine under submerged (water) condition. The workpiece material used for experimenting consisted of AZ31B alloy plates. 27 experiments forming Taguchi's orthogonal array were used for the experiments. SFSP was conducted on the surface of the AZ31B alloy sheets of $6 \mathrm{~mm}$ thickness.

The FSP tool was mounted on the FSW/FSP machine (3-axis servo controlled) and the extruded AZ31B plates were placed using a special fixture fabricated and kept inside an acrylic tank fixed to the machine table. The decision hierarchy structure obtained for the SFSP process is presented in Fig. 2.

The entire experimental setup and the workpiece were firmly clamped to the fixture as shown in Fig. 3.

The process parameters considered for the experiments are traverse speed, rotational speed, and tool

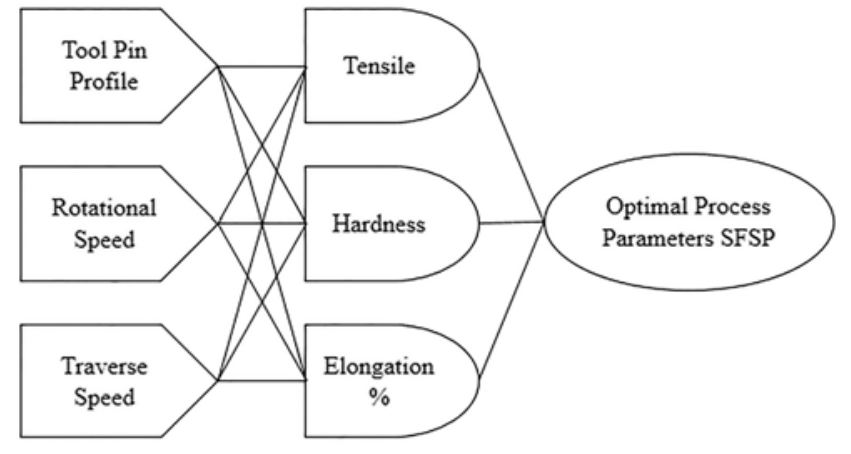

Fig. 2. Decision hierarchy structure.

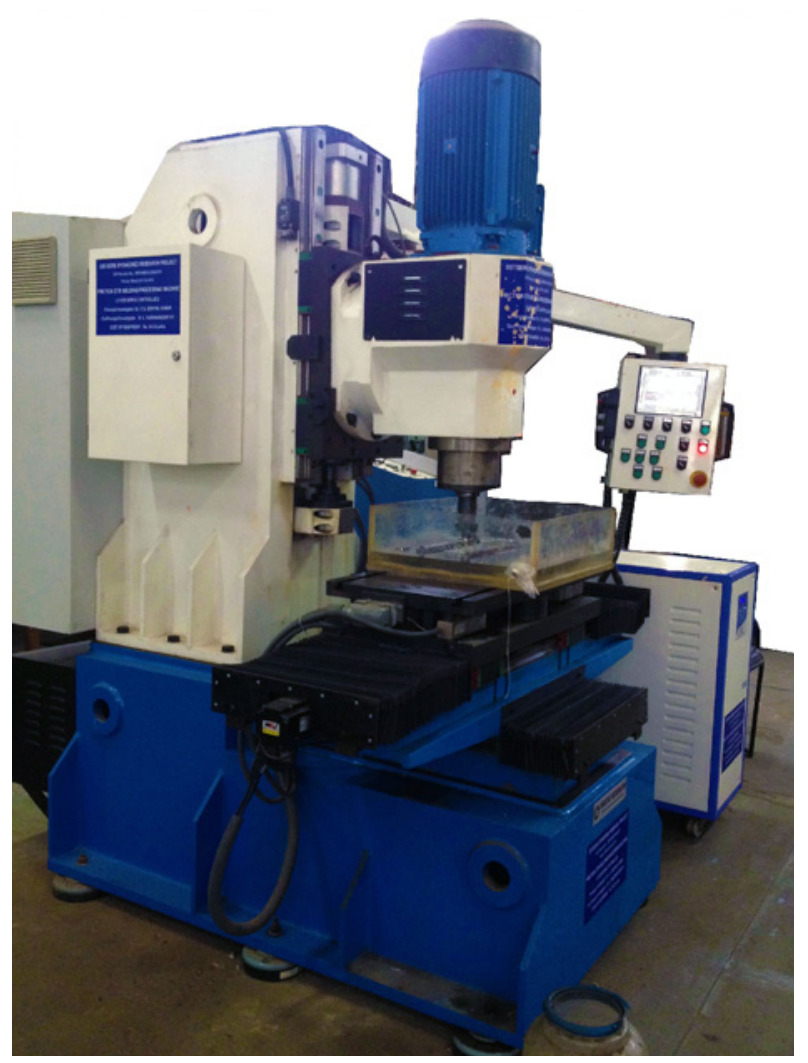

Fig. 3. Experimental setup.

pin profile. The levels have been chosen based on the available literature and availability of the relevant machine. The process parameters considered and their levels chosen are presented in Table 3 .

The responses considered for the analysis of the submerged friction stir processed plates are the ultimate tensile strength (UTS), microhardness (HV), and elongation (\%). The tensile test was conducted by an INSTRON universal testing machine having a capacity of $50 \mathrm{kN}$. A standard tensile test specimen $20 \mathrm{~mm}$ in length and a width of $6 \mathrm{~mm}$ was cut using wire-cut EDM through the ASTM standard E 2448. 
Ta b le 3. Details of levels of a factor with process parameters

\begin{tabular}{llrrr}
\hline & & \multicolumn{3}{c}{ Level } \\
\cline { 3 - 5 } Factor & Process parameters & 1 & 2 & 3 \\
\hline A & Tool pin profile & CL & SCL & SSQ \\
B & Tool rotational speed $(\mathrm{rpm})$ & 800 & 1000 & 1200 \\
C & Traverse speed $\left(\mathrm{mm} \mathrm{min}^{-1}\right)$ & 30 & 60 & 90 \\
\hline
\end{tabular}

The tensile specimen used for conducting experiments and the dimensions of the specimen are presented in Fig. 4. Microhardness values were measured using a Vickers microhardness testing machine. The experimental results are shown in Table 4 . The parameters, namely elongation and UTS, were measured by using a computer interface.

SFSP is an important process currently used in industries for obtaining grains refined with improved properties. Multiple performance optimizations in the SFSP of components are needed in industries. The

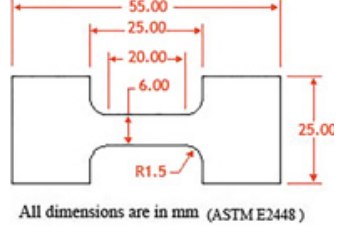

Fig. 4. Tensile test sample geometry.

Table 4 . Best settings of parameters as per $\mathrm{L}_{27}$ orthogonal array

\begin{tabular}{|c|c|c|c|c|c|c|}
\hline \multicolumn{4}{|c|}{ Input parameters } & \multicolumn{3}{|c|}{ Output parameters } \\
\hline Ex.No & $\begin{array}{l}\text { Pin } \\
\text { profile } \\
\text { (A) }\end{array}$ & $\begin{array}{l}\text { Rotational speed } \\
\text { (rpm) } \\
\text { (B) }\end{array}$ & $\begin{array}{c}\text { Traverse speed } \\
\left(\mathrm{mm}_{(\mathrm{min}}^{-1}\right) \\
(\mathrm{C})\end{array}$ & $\begin{array}{c}\text { UTS } \\
(\mathrm{MPa})\end{array}$ & $\begin{array}{l}\text { Microhardness } \\
\quad(\mathrm{HV})\end{array}$ & $\begin{array}{c}\text { Elongation } \\
(\%)\end{array}$ \\
\hline 1 & CL & 800 & 30 & 100.56 & 60.10 & 10.30 \\
\hline 2 & $\mathrm{CL}$ & 800 & 60 & 142.15 & 66.90 & 15.17 \\
\hline 3 & $\mathrm{CL}$ & 800 & 90 & 105.96 & 63.00 & 14.79 \\
\hline 4 & CL & 1000 & 30 & 140.95 & 89.00 & 12.94 \\
\hline 5 & $\mathrm{CL}$ & 1000 & 60 & 162.68 & 90.20 & 15.43 \\
\hline 6 & CL & 1000 & 90 & 152.83 & 86.00 & 16.57 \\
\hline 7 & CL & 1200 & 30 & 131.16 & 95.00 & 15.45 \\
\hline 8 & CL & 1200 & 60 & 156.23 & 86.00 & 17.67 \\
\hline 9 & $\mathrm{CL}$ & 1200 & 90 & 154.41 & 70.40 & 17.39 \\
\hline 10 & SCL & 800 & 30 & 147.17 & 75.00 & 17.73 \\
\hline 11 & SCL & 800 & 60 & 175.31 & 83.60 & 23.27 \\
\hline 12 & SCL & 800 & 90 & 148.49 & 76.90 & 19.79 \\
\hline 13 & SCL & 1000 & 30 & 151.86 & 90.60 & 17.82 \\
\hline 14 & SCL & 1000 & 60 & 169.66 & 89.10 & 19.07 \\
\hline 15 & SCL & 1000 & 90 & 165.34 & 72.80 & 18.79 \\
\hline 16 & SCL & 1200 & 30 & 130.83 & 82.50 & 18.49 \\
\hline 17 & SCL & 1200 & 60 & 145.97 & 88.30 & 19.97 \\
\hline 18 & SCL & 1200 & 90 & 120.90 & 79.40 & 18.99 \\
\hline 19 & SSQ & 800 & 30 & 170.06 & 89.00 & 19.74 \\
\hline 20 & SSQ & 800 & 60 & 173.73 & 99.10 & 20.35 \\
\hline 21 & SSQ & 800 & 90 & 146.14 & 90.90 & 19.51 \\
\hline 22 & SSQ & 1000 & 30 & 222.58 & 97.30 & 18.46 \\
\hline 23 & SSQ & 1000 & 60 & 236.02 & 110.00 & 21.67 \\
\hline 24 & SSQ & 1000 & 90 & 232.00 & 87.80 & 22.89 \\
\hline 25 & SSQ & 1200 & 30 & 220.57 & 99.90 & 21.56 \\
\hline 26 & SSQ & 1200 & 60 & 242.00 & 90.00 & 22.38 \\
\hline 27 & SSQ & 1200 & 90 & 212.00 & 83.90 & 25.50 \\
\hline
\end{tabular}

achievement of multiple performances is a task of great significance. Many multiple performance optimization techniques are available for process optimization. TOPSIS is one of the important methods used for achieving multiple qualities as suggested by researchers [26].

TOPSIS was initiated by Hwang and Yoon. It is referred to as the perfect area multi-criteria selection investigation technique. The primary objective of TOPSIS is the determination of the closest value from a positive solution $\left(S^{+}\right)$and the largest value from a 
Ta ble 5. The calculated normalized decision value and weighted normalized values

\begin{tabular}{|c|c|c|c|c|c|c|}
\hline \multirow{2}{*}{ Sl. No. } & \multicolumn{3}{|c|}{ Normalized decision values } & \multicolumn{3}{|c|}{ Weighted normalized values } \\
\hline & $\begin{array}{c}\text { UTS } \\
(\mathrm{MPa})\end{array}$ & $\begin{array}{l}\text { Microhardness } \\
(\mathrm{HV})\end{array}$ & $\begin{array}{c}\text { Elongation } \\
(\%)\end{array}$ & $\begin{array}{l}\text { UTS } \\
(\mathrm{MPa})\end{array}$ & $\begin{array}{l}\text { Microhardness } \\
\quad(\mathrm{HV})\end{array}$ & $\begin{array}{c}\text { Elongation } \\
(\%)\end{array}$ \\
\hline 1 & 0.114 & 0.135 & 0.105 & 0.037 & 0.044 & 0.034 \\
\hline 2 & 0.161 & 0.150 & 0.154 & 0.053 & 0.049 & 0.051 \\
\hline 3 & 0.120 & 0.141 & 0.150 & 0.039 & 0.046 & 0.049 \\
\hline 4 & 0.160 & 0.199 & 0.132 & 0.052 & 0.065 & 0.043 \\
\hline 5 & 0.184 & 0.202 & 0.157 & 0.060 & 0.066 & 0.051 \\
\hline 6 & 0.173 & 0.193 & 0.169 & 0.057 & 0.063 & 0.055 \\
\hline 7 & 0.148 & 0.213 & 0.157 & 0.049 & 0.070 & 0.052 \\
\hline 8 & 0.177 & 0.193 & 0.180 & 0.058 & 0.063 & 0.059 \\
\hline 9 & 0.175 & 0.158 & 0.177 & 0.057 & 0.052 & 0.058 \\
\hline 10 & 0.167 & 0.168 & 0.180 & 0.055 & 0.055 & 0.059 \\
\hline 11 & 0.199 & 0.187 & 0.237 & 0.065 & 0.061 & 0.078 \\
\hline 12 & 0.168 & 0.172 & 0.201 & 0.055 & 0.057 & 0.066 \\
\hline 13 & 0.172 & 0.204 & 0.182 & 0.057 & 0.067 & 0.060 \\
\hline 14 & 0.192 & 0.200 & 0.195 & 0.064 & 0.066 & 0.064 \\
\hline 15 & 0.187 & 0.164 & 0.192 & 0.062 & 0.054 & 0.063 \\
\hline 16 & 0.148 & 0.185 & 0.189 & 0.049 & 0.061 & 0.062 \\
\hline 17 & 0.165 & 0.198 & 0.204 & 0.055 & 0.065 & 0.067 \\
\hline 18 & 0.137 & 0.178 & 0.194 & 0.045 & 0.059 & 0.064 \\
\hline 19 & 0.193 & 0.200 & 0.201 & 0.064 & 0.066 & 0.066 \\
\hline 20 & 0.197 & 0.223 & 0.208 & 0.065 & 0.073 & 0.069 \\
\hline 21 & 0.165 & 0.204 & 0.199 & 0.055 & 0.067 & 0.066 \\
\hline 22 & 0.252 & 0.219 & 0.188 & 0.083 & 0.072 & 0.062 \\
\hline 23 & 0.268 & 0.247 & 0.221 & 0.088 & 0.082 & 0.073 \\
\hline 24 & 0.263 & 0.197 & 0.234 & 0.087 & 0.065 & 0.077 \\
\hline 25 & 0.250 & 0.224 & 0.220 & 0.083 & 0.074 & 0.073 \\
\hline 26 & 0.274 & 0.202 & 0.228 & 0.091 & 0.067 & 0.075 \\
\hline 27 & 0.240 & 0.188 & 0.260 & 0.079 & 0.062 & 0.086 \\
\hline
\end{tabular}

negative solution $\left(S^{-}\right)$. The assignment of weightages is assigned in this technique to each of the SFSP responses.

In TOPSIS, the units of all responses are removed and the responses are transferred into normalized values. This value $\left(r_{i j}\right)$ is actually accomplished by applying Eq. (1):

$$
r_{i j}=\frac{X_{i j}}{\sqrt{\sum_{i=1}^{9} X_{i j}^{2}}} ; i=1,2,3, \ldots, 27 ; j=1,2,3,
$$

where $i=27$ experiments, $j=3$ output responses and $X_{i j}$ is observed value of the $j^{\text {th }}$ experiments.

The actual weighted normalized value $V_{i j}$ is the obtained product of the normalized values and their weights and is revealed in Eq. (2):

$$
v_{i j}=w_{j} r_{i j} ; i=1,2,3, \ldots, 27 ; j=1,2,3 .
$$

Here, weightage of equal level is given to each response [27]. Therefore, $w_{j}=0.50$. The values obtained through normalization and the weighted normalized values are listed in Table 5.
After calculating the weighted normalized values, the $S^{+}$and $S^{-}$are derived from the Eqs. (3) and (4):

$$
\begin{aligned}
S^{+}= & \left\{\left(\operatorname{Max}\left(v_{i j}\right) \mid j \in J\right),\left(\operatorname{Min}\left(v_{i j}\right) \mid j \in J^{1}\right) \mid\right. \\
& i=1,2,3, \ldots, 27\}, \\
S^{-}= & \left\{\left(\operatorname{Min}\left(v_{i j}\right) \mid j \in J\right),\left(\operatorname{Max}\left(v_{i j}\right) \mid j \in J^{1}\right) \mid\right. \\
& i=1,2,3, \ldots, 27\},
\end{aligned}
$$

where $S^{+}=[0.090712,0.081543,0.034680], S^{+}$signifies a positive (+ve) ideal solution and $S^{-}$signifies a negative $\left(-\right.$ ve) ideal solution, and $S^{-}=[0.037695$, $0.044552,0.085858]$ values are determined, if the $j^{\text {th }}$ criteria have a poor performance.

Alternatives are separated as the $S^{+}$and $S^{-}$which are initiated as per Eqs. (5) and (6):

$$
\begin{aligned}
& D_{i}^{+}=\sqrt{\sum_{i=1}^{9}\left(v_{i j}-s_{j}^{+}\right)^{2}} ; i=1,2,3, \ldots, 27, \\
& D_{i}^{-}=\sqrt{\sum_{i=1}^{9}\left(v_{i j}-s_{j}^{-}\right)^{2}} ; i=1,2,3, \ldots, 27 .
\end{aligned}
$$


Table 6. The calculated (+ve) and (-ve) ideal solution and closeness coefficient

\begin{tabular}{|c|c|c|c|c|c|c|c|}
\hline \multirow{2}{*}{ Sl. No. } & \multicolumn{3}{|c|}{ The positive and negative ideal solution } & \multicolumn{4}{|c|}{ Closeness coefficient } \\
\hline & $\begin{array}{c}\text { UTS } \\
(\mathrm{MPa})\end{array}$ & $\begin{array}{l}\text { Microhardness } \\
\quad(\mathrm{HV})\end{array}$ & $\begin{array}{c}\text { Elongation } \\
(\%)\end{array}$ & $D^{i+}$ & $D^{i-}$ & $C i$ & Rank \\
\hline 1 & 0.038 & 0.045 & 0.035 & 0.065 & 0.051 & 0.442 & 16 \\
\hline 2 & 0.053 & 0.050 & 0.051 & 0.052 & 0.038 & 0.426 & 17 \\
\hline 3 & 0.040 & 0.047 & 0.050 & 0.064 & 0.036 & 0.363 & 25 \\
\hline 4 & 0.053 & 0.066 & 0.044 & 0.042 & 0.050 & 0.543 & 6 \\
\hline 5 & 0.061 & 0.067 & 0.052 & 0.037 & 0.047 & 0.556 & 5 \\
\hline 6 & 0.057 & 0.064 & 0.056 & 0.043 & 0.041 & 0.484 & 10 \\
\hline 7 & 0.049 & 0.070 & 0.052 & 0.046 & 0.044 & 0.488 & 9 \\
\hline 8 & 0.059 & 0.064 & 0.059 & 0.044 & 0.039 & 0.466 & 14 \\
\hline 9 & 0.058 & 0.052 & 0.059 & 0.050 & 0.035 & 0.410 & 20 \\
\hline 10 & 0.055 & 0.056 & 0.060 & 0.051 & 0.033 & 0.397 & 21 \\
\hline 11 & 0.066 & 0.062 & 0.078 & 0.054 & 0.034 & 0.385 & 23 \\
\hline 12 & 0.056 & 0.057 & 0.067 & 0.053 & 0.029 & 0.353 & 26 \\
\hline 13 & 0.057 & 0.067 & 0.060 & 0.045 & 0.039 & 0.469 & 12 \\
\hline 14 & 0.064 & 0.066 & 0.064 & 0.043 & 0.040 & 0.482 & 11 \\
\hline 15 & 0.062 & 0.054 & 0.063 & 0.049 & 0.034 & 0.413 & 19 \\
\hline 16 & 0.038 & 0.045 & 0.035 & 0.065 & 0.051 & 0.442 & 24 \\
\hline 17 & 0.053 & 0.050 & 0.051 & 0.052 & 0.038 & 0.426 & 22 \\
\hline 18 & 0.040 & 0.047 & 0.050 & 0.064 & 0.036 & 0.363 & 27 \\
\hline 19 & 0.053 & 0.066 & 0.044 & 0.042 & 0.050 & 0.543 & 13 \\
\hline 20 & 0.061 & 0.067 & 0.052 & 0.037 & 0.047 & 0.556 & 8 \\
\hline 21 & 0.057 & 0.064 & 0.056 & 0.043 & 0.041 & 0.484 & 18 \\
\hline 22 & 0.049 & 0.070 & 0.052 & 0.046 & 0.044 & 0.488 & 1 \\
\hline 23 & 0.059 & 0.064 & 0.059 & 0.044 & 0.039 & 0.466 & 2 \\
\hline 24 & 0.058 & 0.052 & 0.059 & 0.050 & 0.035 & 0.410 & 7 \\
\hline 25 & 0.055 & 0.056 & 0.060 & 0.051 & 0.033 & 0.397 & 3 \\
\hline 26 & 0.066 & 0.062 & 0.078 & 0.054 & 0.034 & 0.385 & 4 \\
\hline 27 & 0.056 & 0.057 & 0.067 & 0.053 & 0.029 & 0.353 & 15 \\
\hline $\mathrm{S}^{+}$ & 0.091 & 0.082 & 0.035 & & & & \\
\hline
\end{tabular}

Ta b le 7. Calculated average closeness coefficient values

\begin{tabular}{lccc}
\hline & & Factor & \\
\cline { 2 - 4 } Level & $\begin{array}{c}\text { Tool pin profile } \\
(\mathrm{A})\end{array}$ & $\begin{array}{c}\text { Rotational speed } \\
(\mathrm{B})\end{array}$ & $\begin{array}{c}\text { Traverse speed } \\
(\mathrm{C})\end{array}$ \\
\hline Level 1 & 0.4641 & 0.4057 & 0.4905 \\
Level 2 & 0.3969 & 0.5307 & 0.4897 \\
Level 3 & 0.5353 & 0.4786 & 0.4160 \\
\hline
\end{tabular}

Finally, the values of the closeness coefficient of each experimental $\left(C_{i}\right)$ are obtained as given in Eq. (7):

$$
C_{i}=\frac{D_{i}^{-}}{D_{i}^{-}+D_{i}^{+}},
$$

where $D_{i}^{-}$and $D_{i}^{+}$signify closeness coefficient value.

The calculated $S^{+}$and $S^{-}$values and closeness coefficient are shown in Table 6 . The analysis and discussion of the results are presented in the next section.

\section{Results and discussion}

Submerged friction stir process is one of the im- portant processes used in industries for modifying the best microstructural change in the surface of the components. It is gaining importance owing to its improved properties. In this investigation, the SFSP process has been carried out for the AZ31B magnesium alloy plate. The TOPSIS method has been used for simultaneous obtaining of multiple performances, and the results are analyzed by using the closeness coefficient.

An analysis of the results has been carried out by using the average response analysis. The average value of the closeness coefficient provides a multiple performance solution for the problem identified. The average response table was prepared from the analysis of the closeness coefficient which is shown in Ta- 


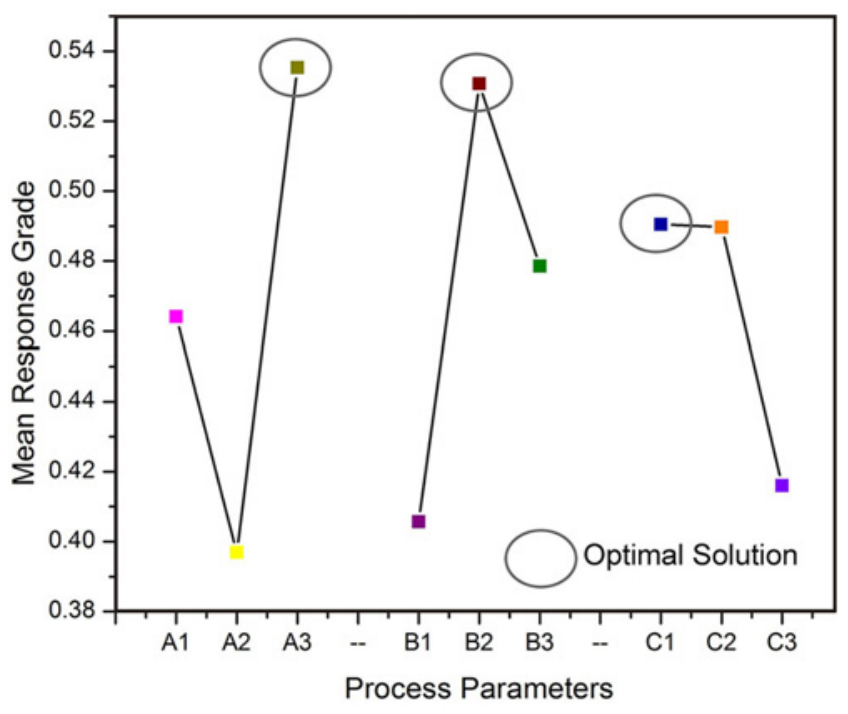

Fig. 5. Response graph for closeness coefficient.

ble 7. A graph has been drawn using the average response and is shown in Fig. 5. The response graph indicates the average result expected for the multiple responses. A study of the graph shows the maximum response grade obtained for the stepped square pin tool (Level 3), $1000 \mathrm{rpm}$ of rotational speed (Level 2) and $30 \mathrm{~mm} \mathrm{~min}^{-1}$ of traverse speed (Level 1) which ensures achievement of a significant ultimate tensile strength, microhardness, and elongation.

The after effects of analysis decide the rate commitment of every parameter. ANOVA helps in formal testing of the importance of every primary component and has connections by contrasting the mean square against an evaluation of the experimental errors at certainty levels [28]. The ANOVA results are presented in Table 8 . This investigation was performed for a $5 \%$ level of significance or $95 \%$ confidence level. A study of Table 8 shows the pin profile of the tool, the traverse and rotational speeds as having significant effects on the output responses considered in the investigation. The influence of the several SFSP parameters is also detailed in Table 8 . The result indicates the tool pin profile as the parameter which influences the SFSP parameters most. The traverse speed has small effect compared to the other parameters considered. The error associated with the process is $7.09 \%$.

The influence of the process parameters which affect the multiple performances in terms of the closeness coefficient is presented in Fig. 6. The effect of the pin profile of the tool at different rotational speeds is presented in Fig. 6a. The figures indicate the stepped tool pin profiles as better than those of the other tools considered, the reason being the capability of the stepped square pin tool to give higher pressure on the workpiece which, in turn, produces a better SFSP
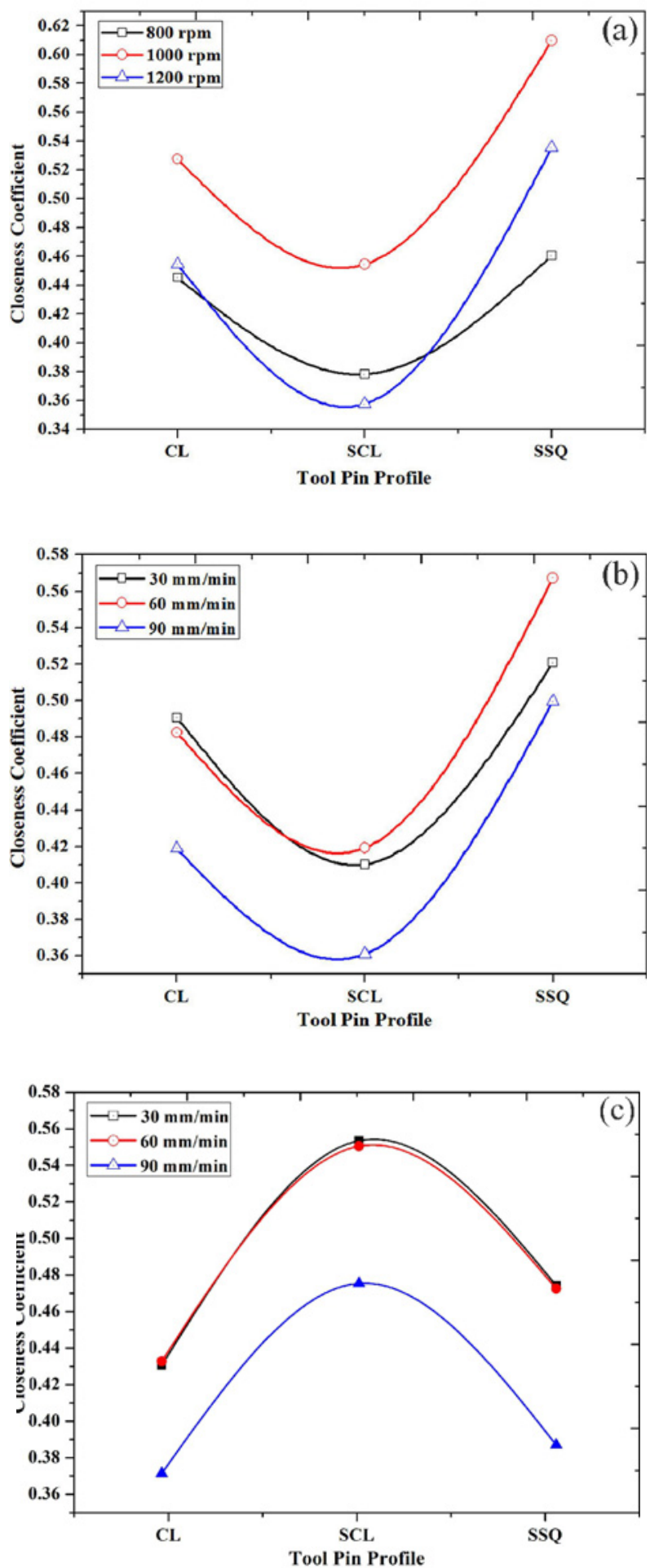

Fig. 6. (a) Effect of tool pin and rotational speed, (b) effect of tool pin and traverse speed, and (c) rotational speed and traverse speed.

profile. Figure 6a also indicates $1000 \mathrm{rpm}$ performing better than the other speeds considered because the slow speed does not modify the proper microstructural change. On the other hand, the high speed produces 
Table 8. Analysis of variance for multiple performances in terms of closeness coefficient

\begin{tabular}{llccccc}
\hline Factor & Process parameters & Degrees of freedom & Sum of squares & Mean sum of squares & $F$-test & Prob $>F$ \\
\hline A & Tool pin profile & 2 & 0.0861 & 0.0430 & 62.20 & $<0.0001$ \\
B & Rotational speed & 2 & 0.0623 & 0.0311 & 45.03 & $<0.0001$ \\
C & Traverse speed & 2 & 0.0329 & 0.0164 & 23.77 & $<0.0001$ \\
Error & & 20 & 0.0138 & 0.0006 & & \\
Total & & 26 & 0.1953 & & & \\
\hline
\end{tabular}

Table 9. Photograph of the processed zone observed

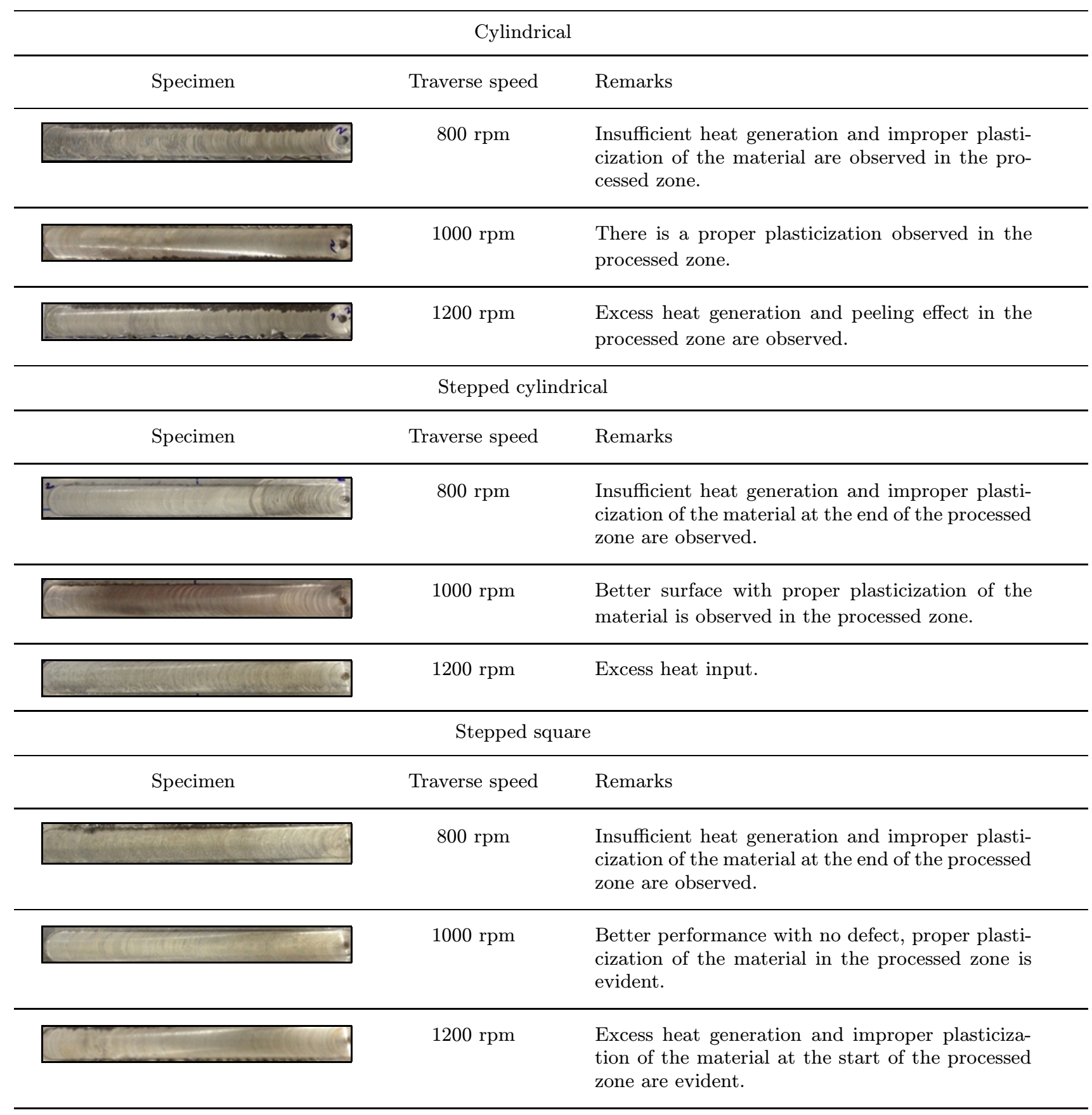

improper microstructural change. This is the reason for better performance at medium speed. The tool pin profiles at the different traverse speeds are presented in Fig. 6b. Almost the same trend is observed here, 

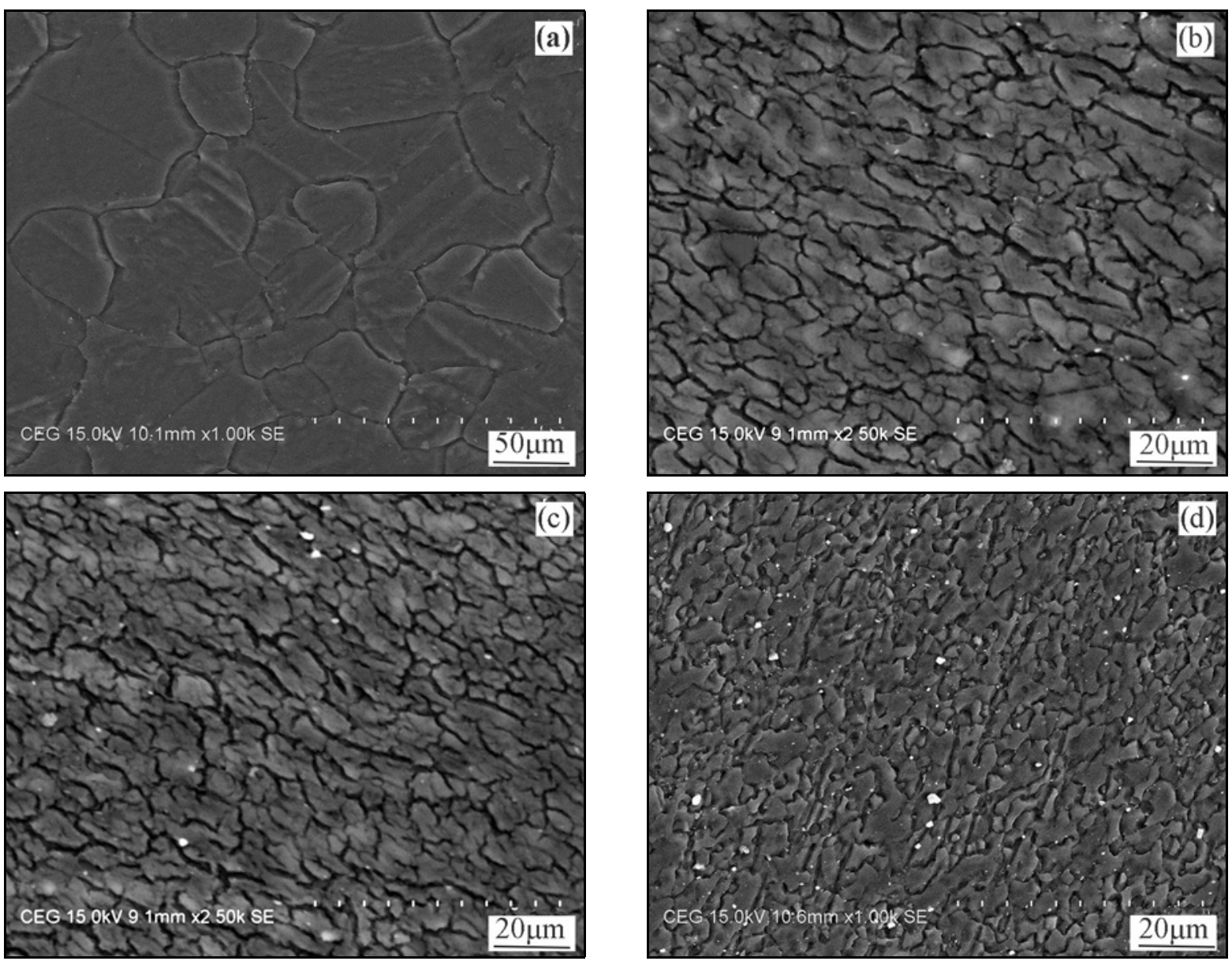

Fig. 7. SEM images of (a) base alloy, (b) cylindrical tool, (c) stepped cylindrical tool, and (d) stepped square tool.

too, i.e., $60 \mathrm{~mm} \mathrm{~min}^{-1}$ traverse speed produces better microstructure changes than compared to other traverse speeds. The effect of rotational speed with respect to traverse speed is presented in Fig. 6c as mentioned earlier. The medium rotational speed and the medium traverse speed produce better microstructural changes. Table 9 shows the processed zone, observed after the SFSP. The table indicates the processed workpiece using three different tool pin profiles at three rotational speeds ranging from 800-1200 rpm by keeping the traverse speed at a maximum of $90 \mathrm{~mm} \mathrm{~min}^{-1}$.

The microstructure of AZ31B magnesium alloys was analyzed using a scanning electron microscope (SEM). The real microstructure of the base alloy observed before the SFSP process is presented in Fig. 7a showing a mean grain size of $96 \mu \mathrm{m}$. The coarse grains indicated by the SEM images are shown in Figs. 7b-d as well as the microstructure observed for three different tool pin profiles at optimal process parameter conditions (rotational speed $1000 \mathrm{rpm}$ and traverse speed $60 \mathrm{~mm} \mathrm{~min}^{-1}$ ), respectively. The SEM images show a microstructural change, wherein the elongated coarse grain structure in the base metal undergoes modifica- tion to a substantial fine grain structure in the nugget zone of the processed samples.

Geometric dynamic recrystallization (GDRX) stirs from the impingement of serrated grain boundaries. Extreme elongation to grains caused by severe hot deformation is a result of the occurrence of these boundaries. There is also the fact of comparability of the wavelength of those serrations to submicron grain size [29]. Figure 7b shows the serrations with the mean grain size of $16 \mu \mathrm{m}$ as the achievement of the cylindrical tool pin profile. Ten-micrometer times in more number of subgrains in the nugget region in comparison with the parent metal is none a byword. Figure $7 \mathrm{c}$ shows the achievement of very fine grains of $12 \mu \mathrm{m}$ in the nugget region. This is a considerable variation from the SEM image of Fig. 7b. Achievement of elongated clear grains $6 \mu \mathrm{m}$ along with larger number subgrains shown in Fig. $7 \mathrm{~d}$ by the stepped square pin profile is seen. The growth of serrations in the original grain boundaries during dynamic retrieval takes place from the SEM image, and the serrated grains touch each other. As a consequence, there is a microstructure of fine equiaxed grains where the size is similar to that of the subgrains in the nugget region. The elon- 
gated grain boundaries are produced by GDRX with severe hot deformation and frictional heat from the rotating stepped pin and shoulder.

The scroll shoulder is considerably effective for the production of the defect-free sample at a higher speed. Also, the scroll shoulder consumes the rotational exploit of the tool through continuous shearing of the workpiece in spiral channels towards the pin, getting forced into the cavity left by the pin later, for producing consolidated welds [30]. This shearing action enhances deformation and frictional heating at the surface. Higher traverse speed becomes feasible as a result of the cylindrical pin not producing any displacement. As a result, the cylindrical pin produces a smaller plastic deformation and stirring of the workpiece. Increased plastic deformation and stirring of the workpiece material by the square pins have enabled the achievement of the highest microhardness value, and fine grain structure while the mechanical properties were recorded in the nugget zone.

Similarly, results were recorded by the square pin based on tensile strength and elongation \%. Increased plastic deformation and stirring of the workpiece produce finer grains within the nugget zone which yield higher microhardness value and tensile strength in turn. The square pin has been indicated as the most effective among the three tool pin shapes for welding at higher welding speeds. Overall, the results indicate that the square pin is most effective among the three tool shapes for welding at higher welding speeds.

\section{Conclusions}

The SFSP of hot-rolled AZ31B magnesium alloy was carried out using three different tool pin profiles investigated in this study. The multiple performance optimization was carried out considering the responses, viz. UTS, microhardness, and elongation. Based on the experimental study, the following conclusions arrived:

- Stepped square pin profile, a rotational rate of $1000 \mathrm{rpm}$ and a traverse rate of $30 \mathrm{~mm} \mathrm{~min}^{-1}$ yielded a maximum value of closeness coefficient reflecting praiseworthy performance at optimal SFSP parameter conditions.

- The percentage contribution of SFSP parameters was determined through the use of ANOVA. The contributions of the pin profile tool, the rotational rate, and traverse rate have been observed to be 59,22 , and $14 \%$, respectively.

- ANOVA demonstrates a significant effect of the SFSP parameters on the output response at the considered confidence level of $95 \%$.

- Improvement of UTS and percentage elongation of the SFSP of AZ31B hot rolled $\mathrm{Mg}$ alloy is seen through the use of the stepped square tool that pro- duced a higher microstructural change.

- The scrolled shoulder achieved superior grain structure, increased microhardness and mechanical properties in the nugget zone of the processed material. Also, the defect-free processed material was obtained.

\section{References}

[1] Mishra, R. S., Ma, Z. Y.: Materials Science and Engineering Reports, 50, 2005, p. 1. doi:10.1016/i.mser.2005.07.001

[2] Besharati-Givi, M. K., Asadi, P.: Advances in Friction-Stir Welding and Processing. Sawston, Woodhead Publishing 2014. ISBN 9780857094544.

[3] Smith, Ch. B., Mishra, R. S.: A Volume in the Friction Stir Welding and Processing Book Series. Oxford, Butterworth-Heinemann 2014.

[4] Darras, B. M., Khraisheh, M. K., Abu-Farha, F. K., Omar, M. A.: Journal of Materials Processing Technology, 191, 2007, p. 77. doi:10.1016/j.jmatprotec.2007.03.045

[5] Del Valle, J. A., Rey, P., Gesto, D., Verdera, D., Jiménez, J. A., Ruano, O. A.: Materials Science \& Engineering A, 628, 2015, p. 198. doi:10.1016/i.msea.2015.01.030

[6] Mohan, A., Yuan, W., Mishra, R. S.: Materials Science \& Engineering A, 562, 2013, p. 69. doi:10.1016/j.msea.2012.11.026

[7] Vivek Patel, V., Vishvesh, J. B., Kumar, A.: Procedia Technology, 23, 2016, p. 537. doi:10.1016/j.protcy.2016.03.060

[8] Motalleb-Nejad, P, Saeid, T., Heidarzadeh, A., Darzi, Kh., Ashjari, M.: Materials \& Design, 59, 2014, p. 221. doi:10.1016/i.matdes.2014.02.068

[9] Elangovan, K., Balasubramanian, V.: Journal of Materials Processing Technology, 200, 2008, p. 163. doi:10.1016/i.jmatprotec.2007.09.019

[10] Babu, S. R., Senthil Kumar, V. S., Madhusudhan Reddy, G., Karunamoorthy, L.: Procedia Engineering, 38, 2012, p. 2956. doi:10.1016/j.proeng.2012.06.345

[11] Karthikeyan, L., Senthil Kumar, V. S., Padmanabhan, K. A.: Materials and Manufacturing Processes, 28, 2013, p. 294. doi:10.1080/10426914.2012.667895

[12] Hofmann, D. C., Vecchio, K. S.: Materials Science and Engineering A, 402, 2005, p. 234. doi:10.1016/j.msea.2005.04.032

[13] Fang, C., Zhang, D. T., Li, Y. Y., Zhang, W. W.: Materials Science and Engineering A, 568, 2013, p. 40. doi:10.1016/j.msea.2013.01.026

[14] Rathinasuriyan, C., Senthil Kumar, V. S.: Kovove Mater., 54, 2016, p. 297. doi:10.4149/km_2016_4_297

[15] Li, J. P., Liu, Y. B., Zhang, S. L., Gong, G., Pan, H.: Kovove Mater., 53, 2015, p. 167. doi:10.4149/km_2015_3_167

[16] Feng. X. L., Liu, H. J., Lippold, J. C.: Materials Characterization, 82, 2013, p. 97. doi:10.1016/j.matchar.2013.05.010

[17] Zhang, H., Liu, H.: Materials \& Design, 45, 2011, p. 206. doi:10.1016/j.matdes.2012.09.022

[18] Darras, B., Kishta, E.: Materials \& Design, 47, 2013, p. 133. doi:10.1016/j.matdes.2012.12.026 
[19] Liu, H. J., Feng, X. L.: Materials \& Design, 47, 2013, p. 101. doi:10.1016/i.matdes.2012.11.056

[20] Santhanam, S. K. V., Rathinaraj, L., Chandran, R. Ramaiyan, S.: In: Proceedings of the International Mechanical Engineering Congress and Exposition 2015. Houston, ASME 2015. Paper No. IMECE2015-50353. doi:10.1115/IMECE2015-50353

[21] Yuvaraj, N., Pradeep Kumar, M.: Materials and Manufacturing Processes, 30, 2015, p. 882. doi:10.1080/10426914.2014.994763

[22] Lokesh, R., Senthil Kumar, V. S., Rathinasuriyan, C., Sankar, R.: International Journal of Technical and Research Applications, 12, 2015, p. 35.

[23] Maity, S. R., Chakraborty, S.: Materials and Manufacturing Processes, 28, 2013, p. 408. doi:10.1080/10426914.2012.700159

[24] Aval, H. J., Loureiro, A.: Kovove Mater., 53, 2015, p. 51. doi:10.4149/km_2015_1_51
[25] Tripathy, S., Tripathy, D. K.: Engineering Science and Technology, 19, 2016, p. 62. doi:10.1016/j.jestch.2015.07.010

[26] Yousefpour, M., Rahimi, A.: Materials \& Design, 54, 2014, p. 382. doi:10.1016/j.matdes.2013.08.017

[27] Lin, Y.-K., Yeh, C.-T.: European Journal of Operational Research, 218, 2012, p. 735. doi:10.1016/j.ejor.2011.11.028

[28] Shah, C., Goyal, B., Patel, V.: Proceedings, 2, 2015, p. 2504. doi:10.1016/j.matpr.2015.07.195

[29] Blum, W., Zhu, Q., Merkel, R., McQueen, H. J.: Materials Science and Engineering A, 205, 1996, p. 23. doi:10.1016/0921-5093(95)09990-5

[30] Trimble, D., O'Donnell, G. E., Monaghan, J.: Journal of Manufacturing Processes, 17, 2015, p. 141. doi:10.1016/i.jmapro.2014.08.007 